\title{
In vitro anti-parasitic activities of Pulicaria dysenterica and Lycopus europaeus methanolic extracts against Trichomonas gallinae
}

\author{
Ali Nikpay ${ }^{1}$, Maryam Soltani ${ }^{2}$ \\ ${ }^{1}$ Department of Pathobiology, Faculty of Veterinary Medicine, Amol University of Special Modern Technologies, Amol, Iran \\ 2 Faculty of Veterinary Medicine, Urmia University, Urmia, Iran
}

\section{A R T I C L E IN F O}

Article Type:

Original Article

\section{Article History:}

Received: 19 October 2017

Accepted: 8 February 2018

\section{Keywords:}

Anti-trichomonas

Pulicaria dysenterica

Lycopus europaeus

Methanolic extract

Trichomonas gallinae

Metronidazole

\begin{abstract}
A B S T R A C T
Introduction: Trichomonas gallinae is the causative agent of trichomoniasis in birds. Although metronidazole is now the drug of choice for treatment of this infection, several studies reported metronidazole-resistant strains of T. gallinae. So it is important to explore for effective alternative compounds such as herbal extracts for treatment of avian trichomoniasis. This study was carried out to investigate the effects of methanolic extracts of Pulicaria dysenteric and Lycopus europaeus on the growth of T. gallinae trophozoites.

Methods: The methanolic extracts were obtained from aerial parts of plants. The anti-trichomonas activities of $P$. dysenterica at the concentrations of 200,100, 50, 25, 12.5 and $6.25 \mathrm{mg} / \mathrm{mL}$ and L. europaeus at the concentrations of 227, 113.5, 56.75, 28.37, 14.1 and $7.09 \mathrm{mg} /$ $\mathrm{mL}$ after $0,1,3$, and 6 hours exposure time were evaluated.

Results: The results showed that both extracts decreased the viability of T. gallinae. The methanolic extract of $P$. dysenteric and L. europaeus showed $10 \%$ and $60 \%$ growth inhibition (GI $\%)$ at the highest concentration immediately after exposure. P. dysenteric methanolic extract at a concentration of $6.25 \mathrm{mg} / \mathrm{mL}$ completely inhibited the growth of parasite after 6 hours which was the minimum inhibitory concentration, while the lowest concentration of L. europaeus extract that showed $100 \%$ GI was $28.37 \mathrm{mg} / \mathrm{mL}$ that affected trophozoites after 6 hours.

Conclusion: Based on the results, both extracts revealed significant growth inhibitory effect on T. gallinae, suggesting the potential use of these plants in preparation of new anti-trichomonas compounds.
\end{abstract}

Implication for health policy/practice/research/medical education:

Methanolic extract of Pulicaria dysenterica and Lycopus europaeus showed remarkable growth inhibitory effects on Trichomonas gallinae trophozoites. Therefore, these extracts might be used as anti-trichomonas agents to treat avian trichomoniasis in future. Please cite this paper as: Nikpay A, Soltani M. In vitro anti-parasitic activities of Pulicaria dysenterica and Lycopus europaeus methanolic extracts against Trichomonas gallinae. J Herbmed Pharmacol. 2018;7(2):112-118. doi: 10.15171/jhp.2018.19.

\section{Introduction}

Avian trichomoniasis is a parasitic disease caused by the protozoan parasite Trichomonas gallinae. Parasites live mainly in the upper area of the digestive tract anterior to the gizzard (1). Depending on the strain virulence, they can live in the tissue of the head, thorax, or abdomen of various groups of birds, counting Columbiformes, Passeriformes, Psittaciformes and Falconiformes (2-4). Among these groups, the family Columbidae is known as the parasite's main host, particularly the domestic pigeon (Columba livia domestica) has been considered responsible for the worldwide spread of T. gallinae (1).

For more than 40 years, the 5-nitroimidazole drugs family, specifically metronidazole and tinidazole, have been used to treat the infections caused by certain gram-negative bacilli and anaerobic parasitic protozoa, especially trichomoniasis $(5,6)$. Currently, metronidazole is the only drug approved for the treatment of T. gallinae. However, 
the existence of resistant strains of T. gallinae to these medications has been observed since the 1990s (6-8). The first therapeutic failures have been described for treatment of avian trichomoniasis. Besides, some metronidazoleresistant strains have been found frequently $(5-7,9)$. Therefore, alternative curative therapies are necessary to provide a substitute treatment for avian trichomoniasis. Recently, the applications of many plants extract instead of chemicals have been recommended as remedies against parasites (10-14). Substances of herbal origin may have anti-trichomonas activities and offer new hope in the treatment of trichomoniasis. Two of the promising antiprotozoa herbal sources are Pulicaria dysenterica and Lycopus europaeus.

The genus Pulicaria, belonging to Asteraceae (Compositae) family, includes 100 species with a distribution from Europe to North Africa and Asia, particularly around the Mediterranean regions (15). Only five species of the genus grow in Iran, which includes $P$. dysenterica, $P$. arabica, $P$. salvifolia, $P$. vulgaris, and $P$. gnaphalodes $(16,17)$.

The chemical literature survey shows the presence of flavonoids, sesquiterpenoids, polyacetylenes, polyacetylenes, sesquiterpenoid lactones, diterpenoids, thymol derivatives, and caryophyllene derivatives in the members of the genus Pulicaria (18-20).

Pulicaria dysenterica (Inula dysenterica), commonly called "Flea-bane" and "Meadow false fleabane", is a persistent plant with $10-30 \mathrm{~cm}$ high, with gold-yellow flowers. It is hermaphrodite and grows on sandy, stony places in Saudi Arabia, Iran, Afghanistan, and western Tibet (16). New compounds including methoxy-12acetoxycaryophylla, methoxycaryophylla-2, dimethoxy12-acetoxycaryophyll-2, hydroxycaryophyll-2, and dihydroxycaryophyll-2 have been isolated from this plant $(18,19)$. In Iran, the original source of this plant is Razavi Khorasan province. $P$. dysenterica commonly is used as a medicinal plant to treat severe heatstroke, diarrhoea, inflammatory, and leishmaniosis diseases (14). Moreover, it has several biological activities such as antioxidant and insecticide properties $(21,22)$.

Lycopus europaeus L. (Labiatae) also known as "gypsywort", is a genus of flowering plants of the Lamiaceae family, which is distributed in Europe, Asia, and the United States. Although active components of L. europaeus are not identified completely, some phytochemical studies on Lycopus spp. show that it contains phenolic compounds, cinnamic acid, rosmarinic acid, caffeic acid, gallic acid, luteolin-7-O-glucuronide, flavonoids, tannins, saponins, lithospermic acid, coumarins, saponins, alkaloids, sterols, caryophyllene, a-pinene, terpinene and terpenoids. Some studies on the extract of $L$. europaeus proved its analgesic and anti-inflammatory activities. L. europaeus is a perennial plant, which is conventionally suggested for treating mild hyperthyroidism. The anti-thyrotropic, antigonadotropic, antioxidant, antimicrobial and cardiotonic effects of this plant are attributed to phenolic compounds, mainly to derivatives of hydroxycinnamic and flavonoids (23-26).

This in vitro research was aimed to study the antitrichomonal activities of methanolic extracts of $P$. dysenterica and L. europaeus in the treatment of T. gallinae and compare the efficacy of these natural products to metronidazole as a standard anti-trichomonal drug. According to available information, this study is the first research demonstrating the potential anti-trichomonal activities of these plants.

\section{Materials and Methods}

In vitro cultivation of parasite

Trichomonas gallinae trophozoites were taken by sterile swabs from the oral cavity, oesophagus and the crop of diseased domestic pigeon (C. livia domestica) with clinical features of trichomonosis and the oral cavity inoculated on Hollander's modification of trypticase yeast extract maltose (TYM) complete medium ( $\mathrm{pH}$ 6.5). The TYM medium contained $10 \mathrm{~g}$ of trypticase peptone, $5 \mathrm{~g}$ of yeast extract, $2.5 \mathrm{~g}$ of maltose, $0.5 \mathrm{~g}$ of $\mathrm{K}_{2} \mathrm{HPO}_{4}, 0.5 \mathrm{~g}$ of $\mathrm{KH}_{2} \mathrm{PO}_{4}$, $0.5 \mathrm{~g}$ of potassium chloride (KCL), $0.5 \mathrm{~g}$ of L-ascorbic acid, $0.5 \mathrm{~g}$ of potassium bicarbonate $\left(\mathrm{KHCO}_{3}\right), 0.05 \mathrm{~g}$ of ferrous sulfate $\left(\mathrm{FeSO}_{4}\right)$, and $0.02 \mathrm{~g}$ of agar (Merck, Germany) per $300 \mathrm{~mL}$ of distilled water. After sterilization of the medium for 15 minutes at $121^{\circ} \mathrm{C}, 30 \mathrm{~mL}$ foetal calf serum (Hyclone, USA) and antibiotic/antimycotic solution containing 0.15 $\mu \mathrm{g} / \mathrm{mL}$ streptomycin, $0.15 \mu \mathrm{g} / \mathrm{mL}$ penicillin, and $0.15 \mu \mathrm{g} /$ $\mathrm{mL}$ amphotericin B, (Sigma-Aldrich, Vienna, Austria) were added to the medium $(27,28)$. Following incubation at $38^{\circ} \mathrm{C}$, motile trichomonads were monitored daily by light microscopy. Isolates were sub-cultured every 48 hours by transferring $500 \mu \mathrm{L}$ of cultured medium into a new sterile $15 \mathrm{~mL}$ Falcon, containing $5 \mathrm{~mL}$ of fresh medium. T. gallinae cells were counted using a haemocytometer (Neubauer Improved, bright line; Germany) and adjusted to $2 \times 10^{7} / \mathrm{mL}$ in the working suspension.

\section{Preparation of methanolic extract}

Aerial parts of $P$. dysenterica and L. europaeus were collected from rural areas of Mazandaran province. The plants were identified by experienced botanists at the faculty of medicinal plants, Amol University of special modern technologies.

The collected plants were washed thoroughly with distilled water and crushed into small pieces to facilitate drying. The pieces of plants were dried at room temperature under shade for three weeks. Finally, the dried plants were powdered using an electric blender and a fine powder was obtained.

Plant extracts were obtained by the following procedures: Three grams of each plant was suspended in $80 \mathrm{ml}$ of $80 \%$ methanol $(\mathrm{v} / \mathrm{v})$. Suspensions were homogenized by vortex for 5 minutes, and the mixtures were placed in 
an ultrasonic bath (Elmasonic $\mathrm{S} 40 \mathrm{H}, 340 \mathrm{~W}, 37 \mathrm{kHz}$ ) at $30^{\circ} \mathrm{C}$ and sonicated for 1 hour. Finally, the extracts were dried using a vacuum rotary evaporator in a water bath at $40^{\circ} \mathrm{C}$ and dried samples were weighed and transferred into the microtubes and stored at $4^{\circ} \mathrm{C}$ until the time of the experiments $(29,30)$.

In vitro anti-trichomonas assay

To explore anti-trichomonas effects of $P$. dysenterica $(200,100,50,25,12.5$ and $6.25 \mathrm{mg} / \mathrm{mL})$ and L. europaeus (227, 113.5, 56.75, 28.37. 14.1 and $7.09 \mathrm{mg} / \mathrm{mL})$ different extract concentrations were diluted in phosphate buffer saline (PBS) and added to the sterile Eppendorf tubes. Approximately $1 \times 10^{7}$ trophozoites $/ \mathrm{mL} \quad$ T. gallinae was added to prepare concentrations of each extract. Metronidazole $(100 \mu \mathrm{g} / \mathrm{mL})$ was utilized as a positive control and PBS was utilized as a negative control. The growth of T. gallinae was observed $0,1,3$, and 6 hours after treatment at $38^{\circ} \mathrm{C}$. Each concentration was replicated three times.

Data analysis

In every sample, in each time live cells of T. gallinae were counted using hemocytometer slide. The active parasites and those with moving flagellum were considered as live cells. Percentage of growth inhibition (GI \%) was calculated and reported using the Eq. 1 where a and b are a; mean numbers of viable parasites in control tube and mean $b$ number of viable parasites in a test tube, respectively (31).

Eq. 1: GI\% $=\mathrm{a}-\mathrm{b} / \mathrm{a} \times 100$.

\section{Statistical analysis}

The study was conducted as factorial based on a randomized design with three replications. Analysis of variance (ANOVA) procedure followed by Duncan's test using SPSS 16 (SPSS Inc., USA) software was applied to determine the significant differences between treatment means. $P$ values of $\leq 0.01$ were considered significant.

\section{Results}

The results showed that both methanolic extracts of $P$. dysenterica and L. europaeus were able to reduce the viability of $T$. gallinae trophozoites by causing cell death at each of the six concentrations. The alive trophozoites were decreased remarkably with enhancing the concentrations of extracts and exposure time.

In general, there was a little difference between the effectiveness of the higher concentrations of methanolic extract of $P$. dysenterica $(200,100$ and $50 \mathrm{mg} / \mathrm{mL}$ ) and L. europaeus $(227,113.5$ and $56.57 \mathrm{mg} / \mathrm{mL}$ ) with these concentrations at 1 hour after exposure (Figures 1 and 2, respectively).

In the highest concentrations of $P$. dysenterica (200 $\mathrm{mg} / \mathrm{mL}$ ) immediately after adding trophozoites to the dilutions, the motile of trophozoites were decreased and growth inhibitory effect was $10 \%$. Exposure to the methanolic extract of $P$. dysenterica at 200, 100, and 50 $\mathrm{mg} / \mathrm{mL}$ concentrations resulted in $100 \%$ cell dead within 1 hour after treatment (Figure 1). Also, 100\% GI was detected with concentrations of $25,12.5$, and $6.25 \mathrm{mg} /$ $\mathrm{mL}$ after 3 and 6 hours after exposure to the methanolic extract of $P$. dysenterica (Table 1).

Moreover, in a dose-dependent and time-dependent manner, the L. europaeus methanolic extract at all different concentrations had significant anti-trichomonal effects $(P \leq 0.01)$ even immediately after exposure to trophozoites of T. gallinae (Table 2). According to Table 2, L. europaeus treated culture showed $60 \%$ inhibition of the growth of parasite with $227 \mathrm{mg} / \mathrm{mL}$ concentration in incubation at 0 hours. The growth inhibitory effect of $L$. europaeus methanolic extract at 227, 113.5, and $56.57 \mathrm{mg} / \mathrm{mL}$ concentrations was $100 \%$ at 1 hour after treatment. The L. europaeus methanolic extract in lower concentrations

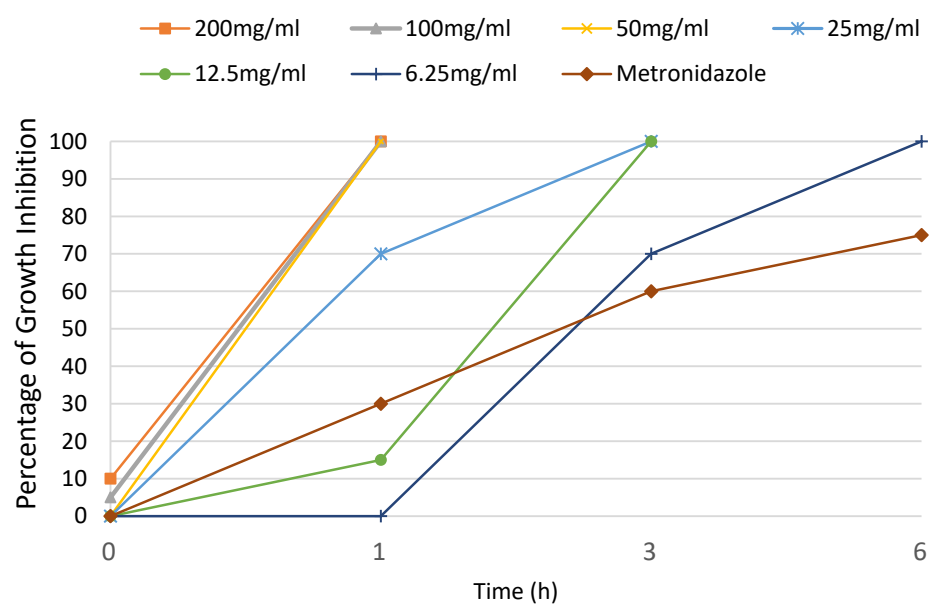

Figure 1. Effect of methanolic extract of Pulicaria dysenterica on Trichomonas gallinae trophozoites in TYM medium following $0,1,3$ and 6 hours after treatment. 


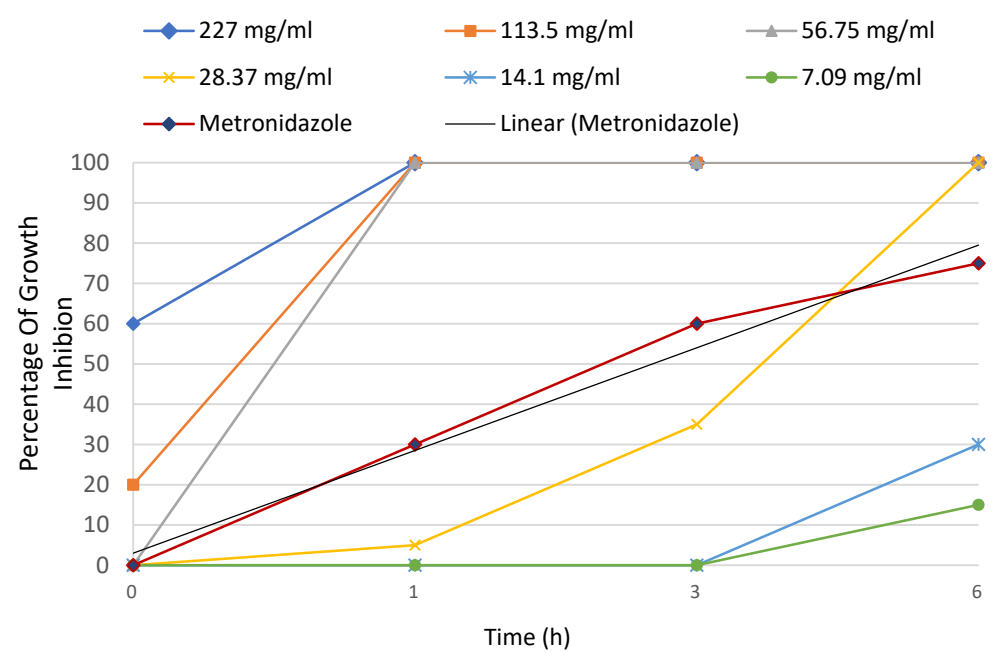

Figure 2. Effect of methanolic extract of Lycopus europaeus on Trichomonas gallinae trophozoites in TYM medium following $0,1,3$ and 6 hours after treatment.

Table 1. Effect of Pulicaria dysenterica methanolic extract on the growth of Trichomonas gallinae trophozoites at different incubation periods

\begin{tabular}{|c|c|c|c|c|c|}
\hline Concentration $(\mathrm{mg} / \mathrm{mL})$ & & 0 & After $1 \mathrm{~h}$ & After $3 \mathrm{~h}$ & After $6 \mathrm{~h}$ \\
\hline \multirow{2}{*}{200} & Mean \pm SD & $10.1^{\mathrm{g}} \pm 2.01^{++, * *}$ & $100^{\mathrm{a}} \pm 0.00^{++, * *}$ & $100^{\mathrm{a}} \pm 0.00^{++,{ }^{*}}$ & $100^{\mathrm{a}} \pm 0.00^{++, * *}$ \\
\hline & GI \% & 10.00 & 100 & 100 & 100 \\
\hline \multirow{2}{*}{100} & Mean \pm SD & $5.02^{h} \pm 0.30^{++}$ & $100^{\mathrm{a}} \pm 0.00^{++, * *}$ & $100^{\mathrm{a}} \pm 0.00^{++, * *}$ & $100^{\mathrm{a}} \pm 0.00^{++, * *}$ \\
\hline & GI \% & 5.00 & 100 & 100 & 100 \\
\hline \multirow{2}{*}{50} & Mean \pm SD & $1.66^{i} \pm 0.30$ & $100^{\mathrm{a}} \pm 0.00^{++, * *}$ & $100^{\mathrm{a}} \pm 0.00^{++, * *}$ & $100^{\mathrm{a}} \pm 0.00^{++, * *}$ \\
\hline & GI \% & 0.00 & 100 & 100 & 100 \\
\hline \multirow{2}{*}{25} & Mean \pm SD & $1.66^{i} \pm 0.41$ & $70.3^{c} \pm 5.01^{++, * *}$ & $100^{\mathrm{a}} \pm 0.00^{++, * *}$ & $100^{\mathrm{a}} \pm 0.00^{++, * *}$ \\
\hline & GI \% & 0.00 & 70.0 & 100 & 100 \\
\hline \multirow{2}{*}{12.5} & Mean \pm SD & $1.66^{i} \pm 0.29$ & $16.66^{f} \pm 2.50^{++}$ & $100^{\mathrm{a}} \pm 0.00^{++, * *}$ & $100^{\mathrm{a}} \pm 0.00^{++, * *}$ \\
\hline & GI \% & 0.00 & 15.00 & 100 & 100 \\
\hline \multirow{2}{*}{6.25} & Mean \pm SD & $1.66^{i} \pm 0.30$ & $1.66^{i} \pm 0.40$ & $70.3^{c} \pm 3.40^{++}$ & $100^{\mathrm{a}} \pm 0.00^{++, * *}$ \\
\hline & GI \% & 0.00 & 0.00 & 70.0 & 100 \\
\hline \multirow{2}{*}{ Parasite Control } & Mean \pm SD & $0.00^{j} \pm 0.00$ & $0.00^{\mathrm{j}} \pm 0.00$ & $0.00^{\mathrm{j}} \pm 0.00$ & $0.00^{j} \pm 0.00$ \\
\hline & GI \% & 0.00 & 0.00 & 0.00 & 0.00 \\
\hline \multirow{2}{*}{ 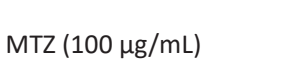 } & Mean \pm SD & $0.00^{j} \pm 0.00$ & $30.33^{e} \pm 2.51^{++}$ & $59.01^{\mathrm{d}} \pm 3.60^{++}$ & $76.33^{b} \pm 3.21^{++}$ \\
\hline & GI \% & 0.00 & 30.00 & 60.00 & 75.00 \\
\hline
\end{tabular}

$\mathrm{SD}$, standard deviation.

$++P<0.01$, statistically significant difference in comparison to parasite control in the same time interval.

** $P<0.01$, statistically significant difference in comparison to metronidazole $100 \mu \mathrm{g} / \mathrm{mL}$ in the same time interval.

Values having no common superscript are significantly different $(P<0.01)$.

showed different results. With a concentration of 28.37 $\mathrm{mg} / \mathrm{mL}, 1.66,5.01$ and $35.01 \%$ prevention of the parasitic growth was found after 0,1 and, $3 \mathrm{~h}$, respectively and complete inhibition of growth (100\%) 6 hours after exposure. Besides, with both concentrations of 14.1 and $7.09 \mathrm{mg} / \mathrm{mL}, 1.66 \%$ inhibition of the parasitic growth was observed after 0,1 , and 3 hours of treatment. At the concentration of $14.1 \mathrm{mg} / \mathrm{mL}$, deterrence of growth was $30 \%$ after 6 hours. Moreover, at the lowest concentration $(7.09 \mathrm{mg} / \mathrm{mL}), 15 \%$ inhibition of growth was found after 6 hours (Table 2).
No remarkable reductions in the number of trophozoites were observed in the control samples. Each concentration showed the statistically significant difference $(P \leq 0.01)$ compared to parasite control and metronidazole groups.

\section{Discussion}

Trichomonas gallinae causes severe tissue lesions in the crop and oesophagus of birds. The only drugs recommended for treating trichomoniasis are metronidazole and a related 5-nitroimidazole, tinidazole, which have been utilized over 40 years. Many studies on clinical resistance 
Table 2. Effect of methanolic extract of Lycopus europaeus on the in vitro growth of Trichomonas gallinae trophozoites after different exposure time

\begin{tabular}{|c|c|c|c|c|c|}
\hline Concentration $(\mathrm{mg} / \mathrm{mL})$ & & 0 & After $1 \mathrm{~h}$ & After $\mathbf{3} \mathbf{h}$ & After $6 \mathrm{~h}$ \\
\hline \multirow{2}{*}{227} & Mean \pm SD & $60^{c} \pm 4.01^{++, * *}$ & $100^{\mathrm{a}} \pm 0.00^{++, * *}$ & $100^{\mathrm{a}} \pm 0.00^{++,{ }^{* *}}$ & $100^{\mathrm{a}} \pm 0.00^{++, * *}$ \\
\hline & GI \% & 60.00 & 100 & 100 & 100 \\
\hline \multirow{2}{*}{113.5} & Mean \pm SD & $20.01^{f} \pm 2.01^{++* *}$ & $100^{\mathrm{a}} \pm 0.00^{++, * *}$ & $100^{\mathrm{a}} \pm 0.00^{++, * *}$ & $100^{\mathrm{a}} \pm 0.00^{++, * *}$ \\
\hline & GI \% & 20.0 & 100 & 100 & 100 \\
\hline \multirow{2}{*}{56.75} & Mean \pm SD & $1.66^{i} \pm 0.30$ & $100^{\mathrm{a}} \pm 0.00^{++, * *}$ & $100^{\mathrm{a}} \pm 0.00^{++, * *}$ & $100^{\mathrm{a}} \pm 0.00^{++, * *}$ \\
\hline & GI \% & 0.00 & 100 & 100 & 100 \\
\hline \multirow{2}{*}{28.37} & Mean \pm SD & $1.66^{i} \pm 0.30$ & $5.01^{h} \pm 1.01^{++}$ & $35.01^{d} \pm 3.01^{++}$ & $100^{\mathrm{a}} \pm 0.00^{++, * *}$ \\
\hline & GI \% & 0.00 & 5.01 & 35.00 & 100 \\
\hline \multirow{2}{*}{14.1} & Mean \pm SD & $1.66^{i} \pm .041$ & $1.66^{i} \pm 0.40$ & $1.66^{i} \pm 0.40$ & $30.1^{\mathrm{e}} \pm 2.01^{++}$ \\
\hline & GI \% & 0.00 & 0.00 & 0.00 & 30.00 \\
\hline \multirow{2}{*}{7.09} & Mean \pm SD & $1.66^{i} \pm 0.39$ & $1.66^{\mathrm{i}} \pm 0.31$ & $1.66^{\mathrm{i}} \pm 0.30$ & $15.01^{g} \pm 2.01^{++}$ \\
\hline & GI \% & 0.00 & 0.00 & 0.00 & 15.00 \\
\hline \multirow{2}{*}{ Parasite control } & Mean \pm SD & $0.00^{j} \pm 0.00$ & $0.00^{j} \pm 0.00$ & $0.00^{j} \pm 0.00$ & $0.00^{j} \pm 0.00$ \\
\hline & GI \% & 0.00 & 0.00 & 0.00 & 0.00 \\
\hline \multirow{2}{*}{ MTZ (100 $\mu \mathrm{g} / \mathrm{mL})$} & Mean \pm SD & $0.00^{j} \pm 0.00$ & $30.33^{\mathrm{e}} \pm 2.51^{++}$ & $59.01^{d} \pm 3.60^{++}$ & $76.33^{b} \pm 3.21^{++}$ \\
\hline & GI \% & 0.00 & 30.00 & 60.00 & 75.00 \\
\hline
\end{tabular}

SD, standard deviation.

$++P<0.01$, statistically significant difference in comparison to parasite control in the same time interval.

** $P<0.01$, statistically significant difference in comparison to metronidazole $100 \mu \mathrm{g} / \mathrm{mL}$ in the same time interval.

Values having no common superscript are significantly different $(P<0.01)$.

of these drugs have been well documented; for example, nitroimidazole resistant of isolates of T. gallinae was found in Belgium, Spain, and the United States $(32,33)$. Nowadays, nitroimidazole resistant strains of $T$. gallinae are prevalent and only a few research have been published on substitutes of anti-trichomonal resources efficient against T. gallinae.

The application of medicinal plants and plant-based drugs has been increased to treat trichomoniasis, especially Trichomonas vaginalis. The effective native medicinal plants of Iran on trichomoniasis include Zataria multiflora, Artemisia absinthium, Taxus baccata, Lavandula intermedia, Achillea millefolium, Pelargonium roseum, Juglans regia, Eucalyptus camaldulensis Dehnh, Stachys lavandulifolia, Artemisia aucheri, Myrtus communis, Freula assafoetida, Tanacetum parthenium, Mentha piperita, Allium sativum, and Salvia officinalis (13).

Pulicaria is used as a medicinal herb, which has been traditionally utilized by humans as an anti-inflammatory remedy to treat severe heatstroke and diarrhoea. Another medicinal plant is Lycopus spp. which has antibacterial and antioxidant effects.

In this study for the first time, the effects of different concentrations of methanolic extracts of $P$. dysenterica and L. europaeus on the axenic culture of T. gallinae trophozoites comparing with metronidazole and negative control were evaluated.

The outcomes revealed that the minimal inhibitory concentrations at 1 hour interval of $P$. dysenterica were 200, 100 and $50 \mathrm{mg} / \mathrm{mL}$, and for L. europaeus were 227,
113.5 and $56.75 \mathrm{mg} / \mathrm{mL}$. The results showed a statistically significant difference compared to metronidazole 100 $\mu \mathrm{g} / \mathrm{mL}$ after 1 hour incubation. The present study demonstrated that even low concentrations of methanolic extract of $P$. dysenterica and L. europaeus could eliminate T. gallinae in medium culture. Data obtained from high concentrations of $P$. dysenterica $(200,100$ and $50 \mathrm{mg} / \mathrm{mL}$ ) and $L$. europaeus $(227,113.5$ and $56.75 \mathrm{mg} / \mathrm{mL}$ ) exhibited strong and rapid anti-trichomonal activity. Also, a $10 \%$ inhibition of growth with $200 \mathrm{mg} / \mathrm{mL}$ concentration of $P$. dysenterica and $60 \%$ GI with a $227 \mathrm{mg} / \mathrm{mL}$ concentration of $L$. europaeus was observed instantly following therapy (0 hours). In lower concentrations of methanolic extract of $P$. dysenterica $(25,12.5$ and $6.25 \mathrm{mg} / \mathrm{mL})$ and $L$. europaeus $(28.37,14.1 \mathrm{mg} / \mathrm{mL})$ longer incubation period (3 and 6 hours) was required to obtain complete loss of viability and motility, while the $7.09 \mathrm{mg} / \mathrm{mL}$ concentration of L. europaeus needed 6 hours to completely inhibit the trophozoites growth. The effect of $P$. dysenterica and $L$. europaeus on the inhibition growth of T. gallinae showed a statistically significant difference compared to parasite control and metronidazole. The results of all extracts revealed that the inhibition of trophozoites growth and trophozoites motility depended on the concentration and incubation time.

These findings are in agreement with the results of Youssefi et al who reported similar inhibitory effect using Artemisia sieberi, and findings of Seddiek et al using garlic against T. gallinae trophozoites in vitro and in vivo assays $(12,34)$. 
Phytochemical studies of Pulicaria spp. and L. europaeus indicated that there were various bioactive components in these plants, which might be responsible for their biological activities. Asghari et al and Zahabi et al reported that P. gnaphalodes extract had a good leishmanicidal effects and it seems that the leishmanicidal activity is mostly associated with the existence of components such as alpha-pinene, borneol, 1,8-cineole, p-cymene, geraniol, and thymol in the essential oils, which have already exhibited leishmanicidal activity $(14,20)$.

Several studies presented an outline of chemical constituents of different Lycopus species. Peng et al isolated various compounds from L. lucidus Turcz and L. europaeus, including terpenoids, flavonoids, phenolic acids, and steroids (35). Fialova et al demonstrated the anti-staphylococcal activity of $L$. europaeus leaves water extract on clinical Staphylococcus aureus strains. Data obtained in their study showed that rosmarinic acid and luteolin-7-O-glucuronide were considered involved in biological activities (26).

According to other studies, biologically active compounds from plant material are mostly affected by dose and incubation time. Under the empirical conditions, increasing the concentrations of extracts from lowest to the highest dose increased the mortality rate of trophozoites of T. gallinae. On the other hands, inhibition of trophozoites growth and trophozoites motility in lower concentrations increased with a constant incubation time. Consequently, the higher the concentration of the extract and the longer the application time, the more significantly lethal effects of the extract.

In conclusion, the present study is the first in vitro investigation evaluating the efficacy of the methanolic extract of $P$. dysenterica and $L$. europaeus against $T$. gallinae trophozoites. Results support our perspective for the possibility of using the methanolic extract of $P$. dysenterica and L. europaeus as anti-trichomonas agents at several concentrations and can suggest the potential use of these plants for treating metronidazole-resistant isolates of T. gallinae. However, more comprehensive studies are needed to survey antitrichomonal activities of methanolic extracts of $P$. dysenterica and L. europaeus in vitro and in vivo conditions.

\section{Acknowledgments}

The authors would like to thank Dr Mojtaba Ranjbar for preparation of herbal extracts.

\section{Conflict of interests}

There is no conflict of interest in this study.

\section{Ethical considerations}

This study protocol was approved by the ethics committee of Amol University of Special Modern Technologies (Ethical code: ir.ausmt.rec.961110). The ethical issues have been observed by the authors.

\section{Funding/Support}

This research has been supported by a research grant from the Amol University of Special Modern Technologies, Amol, Iran (Grant No: 960123)

\section{References}

1. Amin A, Bilic I, Liebhart D, Hess M. Trichomonads in birds--a review. Parasitology. 2014;141(6):733-47. doi: $10.1017 / \mathrm{s} 0031182013002096$.

2. Bunbury N, Jones CG, Greenwood AG, Bell DJ. Trichomonas gallinae in Mauritian columbids: implications for an endangered endemic. J Wildl Dis. 2007;43(3):399407. doi: 10.7589/0090-3558-43.3.399.

3. Krone O, Altenkamp R, Kenntner N. Prevalence of Trichomonas gallinae in northern goshawks from the Berlin area of northeastern Germany. J Wildl Dis. 2005;41(2):3049. doi: 10.7589/0090-3558-41.2.304.

4. Atkinson CT, Thomas NJ, Hunter DB. Parasitic diseases of wild birds. John Wiley \& Sons; 2009.

5. Dingsdag SA, Hunter N. Metronidazole: an update on metabolism, structure-cytotoxicity and resistance mechanisms. J Antimicrob Chemother. 2018;73(2):265-79. doi: $\quad 10.1093 / \mathrm{jac} / \mathrm{dkx} 351$.

6. Dunne RL, Dunn LA, Upcroft P, O’Donoghue PJ, Upcroft JA. Drug resistance in the sexually transmitted protozoan Trichomonas vaginalis. Cell Res. 2003;13(4):239-49. doi: 10.1038/sj.cr.7290169.

7. Zimre-Grabensteiner E, Arshad N, Amin A, Hess M. Genetically different clonal isolates of Trichomonas gallinae, obtained from the same bird, can vary in their drug susceptibility, an in vitro evidence. Parasitol Int. 2011;60(2):213-5. doi: 10.1016/j.parint.2011.02.003.

8. Upcroft P, Upcroft JA. Drug targets and mechanisms of resistance in the anaerobic protozoa. Clin Microbiol Rev. 2001;14(1):150-64. doi: 10.1128/cmr.14.1.150-164.2001.

9. Cudmore SL, Delgaty KL, Hayward-McClelland SF, Petrin DP, Garber GE. Treatment of infections caused by metronidazole-resistant Trichomonas vaginalis. Clin Microbiol Rev. 2004;17(4):783-93. doi: 10.1128/ cmr.17.4.783-793.2004.

10. Khater HF. Prospects of botanical biopesticides in insect pest management. Pharmacologia. 2012;3(12):641-56. doi: 10.5567/pharmacologia.2012.641.656.

11. Khater HF. Ecosmart biorational insecticides: alternative insect control strategies. In: Insecticides-Advances in Integrated Pest Management. InTech; 2012.

12. Seddiek Sh A, El-Shorbagy MM, Khater HF, Ali AM. The antitrichomonal efficacy of garlic and metronidazole against Trichomonas gallinae infecting domestic pigeons. Parasitol Res. 2014;113(4):1319-29. doi: 10.1007/s00436014-3771-6.

13. Shabanian S, Kazemi-Vardanjani A, Bahmani M. Trichomoniasis phytotherapy: an overview of the most important medicinal plants affecting Trichomonas vaginalis. J Chem Pharm Sci. 2016;9(3):1255-62.

14. Zahabi F, Asghari GR, Eskandarian A, Yousefi $H$. Leishmanicidal activity of Pulicaria gnaphalodes. Res Pharm Sci. 2012;7(5):S801. 
15. Williams CA, Harborne JB, Greenham JR, Grayer RJ, Kite GC, Eagles J. Variations in lipophilic and vacuolar flavonoids among European Pulicaria species. Phytochemistry. 2003;64(1):275-83. doi: 10.1016/S0031-9422(03)00207-3.

16. Moazaffarian V. A Dictionary of Iranian Plant Names: Latin-English-Persian. Tehran: Farhang Moaser; 2008.

17. Zarin P, Ghahremaninejad F, Maassoumi AA. Systematic of genera Pulicaria Gaertn. and Platycheteae Boiss. from tribe Inuleae s.str (Asteraceae) in Iran. Taxonomy and Biosystematics Journal. 2010;2(2):27-44.

18. Al-Hajj NQM, Ma C, Thabit R, Gasmalla MA, Ahmed Mohammed A, Aboshora W, et al. Chemical composition of essential oil and mineral contents of Pulicaria inuloides. Journal of Academia and Industrial Research. 2014;2(12):675-8.

19. Liu LL, Yang JL, Shi YP. Phytochemicals and biological activities of Pulicaria species. Chem Biodivers. 2010;7(2):327-49. doi: 10.1002/cbdv.200900014.

20. Asghari G, Zahabi F, Eskandarian A, Yousefi H, Asghari M. Chemical composition and leishmanicidal activity of Pulicaria gnaphalodes essential oil. Research Journal of Pharmacognosy. 2014;1(4):27-33.

21. Ebadollahi A. Iranian plant essential oils as sources of natural insecticide agents. Int J Biol Chem. 2011;5(5):26690. doi: 10.3923/ijbc.2011.266.290.

22. Shariatifar N, Kamkar A, Shams Ardekani MR, Misaghi A, Jamshidi AH, Jahed Khaniki GR. Quantitative and qualitative study of phenolic compounds and antioxidant activity of plant Pulicaria gnaphalodes. Ofogh-E-Danesh. 2012;17(4):35-41.

23. Aziz A, Khan IA, Hussain M, Afzal A, Ahmed MB, Munawar SH, et al. Antinociceptive and anti-inflammatory activity of the extract of lycopus europaeus on laboratory animals. Int J Res Dev Pharm Life Sci. 2014;3(2):896-904.

24. Beer AM, Wiebelitz KR, Schmidt-Gayk H. Lycopus europaeus (Gypsywort): effects on the thyroidal parameters and symptoms associated with thyroid function. Phytomedicine. 2008;15(1-2):16-22. doi: 10.1016/j. phymed.2007.11.001.

25. Radulovic N, Denic M, Stojanovic-Radic Z. Antimicrobial phenolic abietane diterpene from Lycopus europaeus L. (Lamiaceae). Bioorg Med Chem Lett. 2010;20(17):4988-91. doi: 10.1016/j.bmcl.2010.07.063.
26. Fialova S, Slobodnikova L, Veizerova L, Grancai D. Lycopus europaeus: phenolic fingerprint, antioxidant activity and antimicrobial effect on clinical Staphylococcus aureus strains. Nat Prod Res. 2015;29(24):2271-4. doi: 10.1080/14786419.2015.1010086.

27. Amin A, Neubauer C, Liebhart D, Grabensteiner E, Hess M. Axenization and optimization of in vitro growth of clonal cultures of Tetratrichomonas gallinarum and Trichomonas gallinae. Exp Parasitol. 2010;124(2):202-8. doi: 10.1016/j. exppara.2009.09.014.

28. Atlas RM. Handbook of Microbiological Media. 4th ed. CRC press; 2010.

29. Falleh H, Ksouri R, Lucchessi ME, Abdelly C, Magne C. Ultrasound-assisted extraction: Effect of extraction time and solvent power on the levels of polyphenols and antioxidant activity of Mesembryanthemum edule L. Aizoaceae shoots. Trop J Pharm Res. 2012;11(2):243-9. doi: 10.4314/tjpr.v11i2.10.

30. Medina-Torres N, Ayora-Talavera T, Espinosa-Andrews $\mathrm{H}$, Sanchez-Contreras A, Pacheco N. Ultrasound assisted extraction for the recovery of phenolic compounds from vegetable sources. Agronomy. 2017;7(3):47. doi: 10.3390/ agronomy7030047.

31. Tabari MA, Youssefi MR, Moghadamnia AA. Antitrichomonal activity of Peganum harmala alkaloid extract against trichomoniasis in pigeon (Columba livia domestica). Br Poult Sci. 2017;58(3):236-41. doi: 10.1080/00071668.2017.1280725.

32. Gerhold RW, Yabsley MJ, Smith AJ, Ostergaard E, Mannan W, Cann JD, et al. Molecular characterization of the Trichomonas gallinae morphologic complex in the United States. J Parasitol. 2008;94(6):1335-41. doi: 10.1645/ge1585.1.

33. Rouffaer LO, Adriaensen C, De Boeck C, Claerebout E, Martel A. Racing pigeons: a reservoir for nitro-imidazoleresistant Trichomonas gallinae. J Parasitol. 2014;100(3):3603. doi: $10.1645 / 13-359.1$.

34. Youssefi MR, Abouhosseini Tabari M, Moghadamnia AA. In vitro and in vivo activity of Artemisia sieberi against Trichomonas gallinae. Iran J Vet Res. 2017;18(1):25-9.

35. Peng T, Yin Z, Yang B, Kang W. Research progress on the chemical constituents of Lycopus genus. Curr Opin Complement Alternat Med. 2014;1(1):28-33. 